\title{
A rare case of chlorhexidine- and clindamycin-induced anaphylaxis
}

\author{
Hao Xiao, Hongting Zhang, Juan Meng
}

\begin{abstract}
Background: Chlorhexidine and clindamycin, especially the latter, rarely cause anaphylaxis.

Objective: To report a rare case of chlorhexidine- and clindamycin-induced anaphylaxis.

Methods: Case report

Results: A 21-year-old female experienced anaphylaxis after receiving intravenous clindamycin after a left big toe fracture fixation operation; she also had a similar reaction after using a mouthwash. Therefore, we suspected the culprit might be chlorhexidine, and the skin prick and serum specific IgE test results confirmed our suspicion. Then the clindamycin provocation test verified that the patient also had hypersensitivity to clindamycin. However, the allergy tests for penicillin and cefuroxime were negative.
\end{abstract}

Conclusion: Only four cases of clindamycin-induced anaphylaxis have been reported, and this is the first report of clindamycin-induced anaphylaxis verified by provocation test. The patient was given clindamycin because she was incorrectly labeled as having penicillin and cephalosporin allergies during the routine allergy test. It is essential to address this problem in China.

Key words: chlorhexidine; clindamycin; anaphylaxis; provocation test; $\beta$-lactam antibiotics

\section{From:}

Allergy Center of Otolaryngology, Head and Neck Surgery

Department, West China Hospital, Sichuan University, Chengdu, China

\section{Introduction}

Chlorhexidine is a topical antibacterial agent and cationic surfactant that can kill most gram-positive and gram-negative bacteria. Contact dermatitis caused by chlorhexidine was first reported in 1965, ${ }^{1}$ and is more common than anaphylaxis resulting from chlorhexidine, which was first reported in $1984 .{ }^{2}$

Clindamycin is a synthetic antibiotic that inhibits bacterial protein synthesis and is used primarily in the treatment of gram-positive and anaerobic infections, especially in patients with $\beta$-lactam allergies. Delayed cutaneous reactions range from $<1 \%$ to $10.5 \%,{ }^{3}$ while immediate hypersensitivity reactions, such as anaphylaxis, are very rare.

\section{Case}

A female (now 21 years old) underwent fracture fixation operation of the left big toe under local anesthesia in December 2008. The surgical process was uneventful. Immediately after the operation, clindamycin was administered intravenously because the patient was labeled as having penicillin

\author{
Corresponding author: \\ Juan Meng \\ E-mail: mjmelinda@163.com
}

and cephalosporin allergies, since she had positive results for a penicillin and a cephalosporin (the exact drugs were not clear) intradermal tests (IDTs) performed during a routine allergy skin test (ST) before B-lactam administration, which was conducted according to Chinese routine clinical practice. Several minutes later, she felt intense itching in her scalp and vaginal mucosa, which was followed by generalized wheals and pruritus, accompanied by tachycardia, blurred vision, hoarseness, and hearing loss. She was given dexamethasone $5 \mathrm{mg}$ intravenously and promethazine $25 \mathrm{mg}$ intramuscularly. Thirty minutes later, she recovered. Since then, she has never received any kind of antibiotics.

In 2011, she used a mouthwash for dental ulcers. Half an hour later, she experienced tachycardia and a feeling of impending death, but her vital signs were normal. Three hours later, she had itchy wheals on her upper and lower limbs and all over her trunk. One hour after treatment, she recovered (the details were unclear). She had no history of other atopic comorbidities or other diseases. 
In January 2019, STs for chlorhexidine, clindamycin, penicillin and cefuroxime were performed on her volar forearm and read after $15 \mathrm{~min}$ (Table 1). Histamine $(10 \mathrm{mg} / \mathrm{ml})$ and diluent (ALK, Horsholm, Denmark) were used as positive and negative controls, respectively. The ST for chlorhexidine was strongly positive (Figure 1), and all the other STs were negative. The serum specific IgE (sIgE) level for chlorhexidine was $1.67 \mathrm{kUA} / \mathrm{L}$, and the sIgE levels for penicilloyl G, penicilloyl $\mathrm{V}$, amoxicillin and ampicillin were $0.02 \mathrm{kUA} / \mathrm{L}$, $0.22 \mathrm{kUA} / \mathrm{L}, 0.03 \mathrm{kUA} / \mathrm{L}$ and $0.02 \mathrm{kUA} / \mathrm{L}$, respectively (ImmunoCap System, ThermoFisher, Uppsala, Sweden). The provocation tests for amoxicillin and cefuroxime were negative, while 10 minutes after $1 / 10$ of the dose $(60 \mathrm{mg})$ of clindamycin was infused, the patient felt intense itching in the scalp, vagina, and trunk, accompanied by trunk skin flushing and chest congestion. The heart rate increased from the baseline rate of $98 \mathrm{bpm}$ to $132 \mathrm{bpm}$, while the blood pressure

Table 1. Skin testing results.

\begin{tabular}{|c|c|c|c|}
\hline Drug & SPT & \multicolumn{2}{|c|}{ IDT } \\
\hline chlorhexidine & $\begin{array}{c}5 \mathrm{mg} / \mathrm{ml} \\
(+)\end{array}$ & $\begin{array}{c}0.002 \mathrm{mg} / \mathrm{ml} \\
\text { (ND) }\end{array}$ & I \\
\hline clindamycin & $\begin{array}{c}6 \mathrm{mg} / \mathrm{ml} \\
(-)\end{array}$ & $\begin{array}{c}0.6 \mathrm{mg} / \mathrm{ml} \\
(-)\end{array}$ & I \\
\hline PPL & $\begin{array}{c}0.04 \mathrm{mg} / \mathrm{ml} \\
(-)\end{array}$ & $\begin{array}{c}0.004 \mathrm{mg} / \mathrm{ml} \\
(-)\end{array}$ & $\begin{array}{c}0.04 \mathrm{mg} / \mathrm{m} \\
(-)\end{array}$ \\
\hline MD & $\begin{array}{c}0.5 \mathrm{mg} / \mathrm{ml} \\
(-)\end{array}$ & $\begin{array}{c}0.05 \mathrm{mg} / \mathrm{ml} \\
(-)\end{array}$ & $\underset{(-)}{0.5 \mathrm{mg} / \mathrm{ml}}$ \\
\hline benzylpenicillin & $\begin{array}{c}6 \mathrm{mg} / \mathrm{ml} \\
(-)\end{array}$ & $\underset{(-)}{6 \mathrm{mg} / \mathrm{ml}}$ & I \\
\hline amoxicillin & $\underset{(-)}{25 \mathrm{mg} / \mathrm{ml}}$ & $\begin{array}{c}2.5 \mathrm{mg} / \mathrm{ml} \\
(-)\end{array}$ & $\underset{(-)}{25 \mathrm{mg} / \mathrm{ml}}$ \\
\hline cefuroxime & $\begin{array}{c}2.5 \mathrm{mg} / \mathrm{ml} \\
(-)\end{array}$ & $\begin{array}{c}0.25 \mathrm{mg} / \mathrm{ml} \\
(-)\end{array}$ & $\begin{array}{c}2.5 \mathrm{mg} / \mathrm{ml} \\
(-)\end{array}$ \\
\hline
\end{tabular}

Abbreviations: SPT, skin prick test; IDT, intradermal test;

PPL, penicilloyl-poly-L-lysine; MD, minor determinant; ND, not done PPL and MD were from Diater Laboratory, Madrid, Spain.

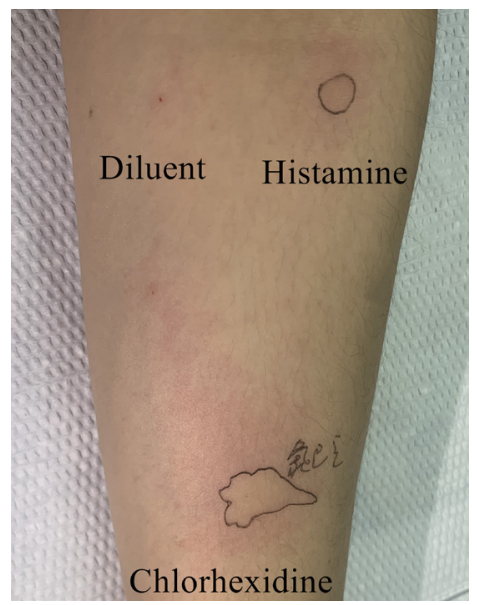

Figure 1. Positive result of the skin prick test for chlorhexidine $(5 \mathrm{mg} / \mathrm{ml})$ and oxygen saturation were normal. She was immediately given diphenhydramine $20 \mathrm{mg}$ intramuscularly, cetirizine $10 \mathrm{mg}$ orally and inhaled oxygen. Her vital signs were closely monitored, and epinephrine $0.5 \mathrm{mg}$ had been prepared and was ready for use at any moment. Ten minutes later, she stabilized. The patient was diagnosed with chlorhexidine and clindamycin allergies, while penicillin and cefuroxime allergies were ruled out. The recommendation was made for her to avoid clindamycin and all the products containing chlorhexidine.

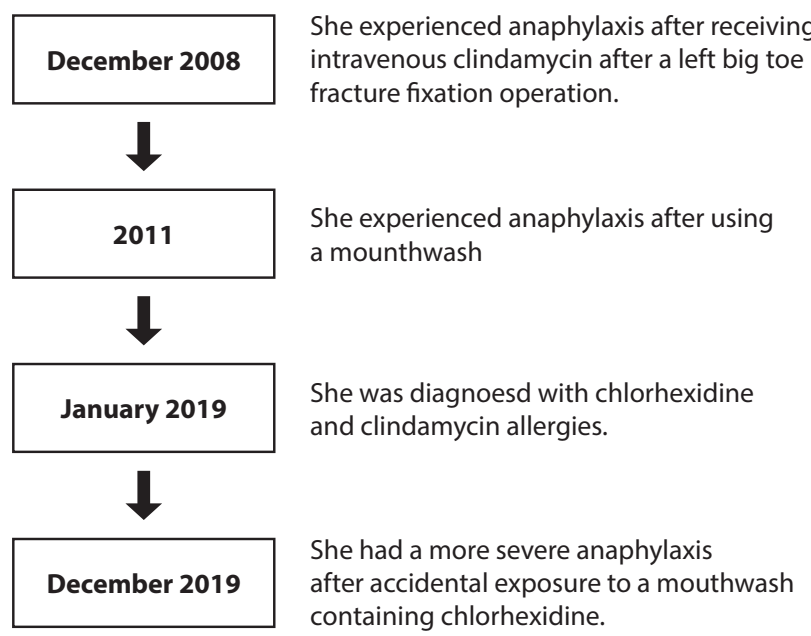

Figure 2. The event timeline of this case.

We did not perform a chlorhexidine provocation test on the patient; however, the patient told us she had a more severe anaphylaxis during a dental treatment in December 2019 (the event timeline is summarized in figure 2). Although she told the dentist she was allergic to chlorhexidine, a mouthwash containing chlorhexidine was given to her. Two minutes later, her pharyngeal mucosa became itchy, and then her lip swelled. Five minutes later, she felt intense itching of her scalp and vaginal mucosa, which was followed by generalized wheals and pruritus, throat tightness, chest congestion, tachycardia, and hypotension, and she rapidly became unconscious. Epinephrine $0.5 \mathrm{mg}$ intramuscularly and dexamethasone $5 \mathrm{mg}$ intravenously was given to her immediately. Approximately 30 minutes later, she recovered. This accidental exposure further verified the diagnosis of chlorhexidine-induced anaphylaxis. In addition, povidone iodine was used as a disinfectant for the patient after diagnosis, and no hypersensitivity reactions appeared.

\section{Discussion}

The use of chlorhexidine in dentistry has increased since the 1970s. It can cause irritation of the oral mucosa and perioral skin as well as severe allergic reactions. In our case, the ST and serum sIgE test results, and anaphylaxis induced by accidental exposure to chlorhexidine verified that she was allergic to chlorhexidine. In addition, during the perioperative period, anaphylaxis caused by chlorhexidine usually occurs 20 to 40 minutes after the administration of the drug. ${ }^{4}$ Based on the patient's clinical history, we first suspected that the culprit drug that induced anaphylaxis immediately 
after surgery might also be chlorhexidine. Therefore, we wanted to rule out clindamycin allergy. However, the positive result of the clindamycin provocation test verified the clindamycin-induced anaphylaxis in this patient.

Clindamycin-induced hypersensitivity reactions are more common with delayed cutaneous reactions, and immediate hypersensitivity reactions such as anaphylaxis are extremely rare. In fact, only four previous case reports of suspected clindamycin-induced anaphylaxis have been published. ${ }^{5-8}$ Three were diagnosed based on the close temporal relationship between the administration of clindamycin and the onset of the reaction, together with the exclusion of alternative causes. ${ }^{5-7}$ One patient received the diagnosis based on the positive results of the IDT and basophil activation test. ${ }^{8}$ To the best of our knowledge, this is the first report of clindamycin-induced anaphylaxis that was verified by provocation test.

The usefulness of ST for clindamycin hypersensitivity is still controversial. Notman et al. demonstrated that although the clinical history indicated that the hypersensitivity reactions might have been IgE-mediated, none of the patients had positive results for the SPT and IDT for clindamycin. ${ }^{9}$ However, Ebo et al. recently reported a case in which clindamycin anaphylaxis was confirmed by a positive reaction to 100 -fold diluted IDT, which was verified to be an irritative concentration. ${ }^{8}$ The exact mechanism of clindamycin-induced anaphylaxis remains poorly understood. Although no sIgE antibody to clindamycin has been discovered thus far, the case reported by Ebo et al. with positive ST results probably indicates an IgE-mediated mechanism. ${ }^{8}$ In our case, the SPT and IDT were negative, and we speculated that the reaction might be non-IgE-mediated or might be caused by unknown degradation products of clindamycin. However, due to the long time interval between the reaction in clinical history and the ST, the possibility of clindamycin sIgE waning overtime could not be ruled out.

According to the patient's clinical history, clindamycin was used because she was labeled as having penicillin and cephalosporin allergies due to false positive results for routine IDT before administration. Although the international consensus strongly recommends against STs before $\beta$-lactam administration in patients with no history of $\beta$-lactam drug hypersensitivity reaction, ${ }^{10}$ because the false positive rate is extremely high, Chinese regulations, such as Pharmacopoeia of the People's Republic of China, and drug instructions still require routine ST screening before the administration of penicillin. Many hospitals even perform routine cephalosporin IDT. Therefore, many patients are incorrectly labeled as being allergic to penicillin and/or cephalosporin, which drives the use of broader-spectrum antibiotics and leads to increased levels of bacterial resistance. Recently, an analysis of paediatric survey data from 56 countries regarding hospital antibiotic use patterns showed that China had the lowest use of Access antibiotics (generally narrow-spectrum antibiotics recommended as first and second choice for most common clinical infection syndromes), ${ }^{11}$ and the performance of STs before the use of penicillins was thought to be one of the main reasons. ${ }^{12}$
In this case, epinephrine was not given to the patient each time she developed anaphylaxis. Jiang et al. recently assessed the initial treatment for anaphylaxis in China by performing a systematic analysis of published case reports between 2014 and 2018 , and found that only $14.2 \%$ of the patients were appropriately treated with epinephrine as the first-line intervention. This highlights the critical gap between the initial treatment of anaphylaxis in China and the recommendations in the international guidelines, and targeted training is urgently needed for healthcare providers in China. ${ }^{13}$

In conclusion, we reported a rare case of chlorhexidineand clindamycin-induced anaphylaxis. Clinicians should be aware of clindamycin-induced anaphylaxis, as it is rare but not impossible. The patient was given clindamycin because she was incorrectly labeled as having penicillin and cephalosporin allergies during a routine allergy screening test. Thus, it is essential to address this problem in China.

\section{Acknowledgments}

This work was supported by grants to Juan Meng from the 1.3.5 Project for Disciplines of Excellence - Clinical Research Incubation Project at West China Hospital of Sichuan University (Grant NO. 2018HXFH026).

\section{References}

1. Restell M. Reaction to Chlorhexidine and Cetrimide. Lancet. 1965;1:918

2. Nishioka K, Doi T, Katayama I. Histamine release in contact urticaria. Contact Dermatitis. 1984;11:191

3. Mazur N, Greenberger PA, Regalado J. Clindamycin hypersensitivity appears to be rare. Ann Allergy Asthma Immunol. 1999;82:443-5.

4. Opstrup MS, Malling HJ, Kroigaard M, Mosbech H, Skov PS, Poulsen LK, et al. Standardized testing with chlorhexidine in perioperative allergy--a large single-centre evaluation. Allergy. 2014;69:1390-6.

5. Bulloch MN, Baccas JT, Arnold S. Clindamycin-induced hypersensitivity reaction. Infection. 2016;44:357-9.

6. Lochmann O, Kohout P, Vymola F. Anaphylactic shock following the administration of clindamycin. J Hyg Epidemiol Microbiol Immunol. 1977; 21: 441-7.

7. Chiou CS, Lin SM, Lin SP, Chang WG, Chan KH, Ting CK. Clindamycin -induced anaphylactic shock during general anesthesia. J Chin Med Assoc. 2006;69:549-51.

8. Ebo DG, Mertens C, Braes M, Mennes I, Bridts CH, Sabato V. Clindamycin anaphylaxis confirmed by in vivo and in vitro testing. J Allergy Clin Immunol Pract. 2019;7:331-3.

9. Notman MJ, Phillips EJ, Knowles SR, Weber EA, Shear NH. Clindamycin skin testing has limited diagnostic potential. Contact Dermatitis. 2005; 53:335-8.

10. Torres MJ, Adkinson NF Jr, Caubet JC, Khan DA, Kidon MI, Mendelson L, et al. AAAAI/WAO 2018 Symposium Penicillin and Cephalosporin Allergy Testing Working Group. Controversies in Drug Allergy: Beta-Lactam Hypersensitivity Testing. J Allergy Clin Immunol Pract. 2019;7:40-5.

11. Hsia Y, Lee BR, Versporten A, Yang Y, Bielicki J, Jackson C, et al. Use of the WHO Access, Watch, and Reserve classification to define patterns of hospital antibiotic use (AWaRe): an analysis of paediatric survey data from 56 countries. Lancet Glob Health. 2019;7:e861-71.

12. Zhang J, Zheng Y, Yang Y. Antibiotic prescription patterns in children and neonates in China. Lancet Glob Health. 2019;7:e1496.

13. Jiang C, Li H, Wang L, Liu C, Hao X. Gaps between actual initial treatment of anaphylaxis in China and international guidelines: A review and analysis of 819 reported cases. Allergy. 2020;75:968-971. 